\title{
Can Obesity Cause Depression? A Pseudo-panel Analysis
}

\author{
Hyungserk Ha' ${ }^{1}$, Chirok Han², Beomsoo Kim²
}

${ }^{1}$ Youth Independence and Competencies Research Office, National Youth Policy Institute, Sejong; ${ }^{2}$ Department of Economics, Korea University, Seoul, Korea

Objectives: The US ranks ninth in obesity in the world, and approximately 7\% of US adults experience major depressive disorder. Social isolation due to the stigma attached to obesity might trigger depression.

Methods: This paper examined the impact of obesity on depression. To overcome the endogeneity problem, we constructed pseudopanel data using the Behavioral Risk Factor Surveillance System from 1997 to 2008.

Results: The results were robust, and body mass index (BMI) was found to have a positive effect on depression days and the percentage of depressed individuals in the population.

Conclusions: We attempted to overcome the endogeneity problem by using a pseudo-panel approach and found that increases in the BMI increased depression days (or being depressed) to a statistically significant extent, with a large effect size.

Key words: Obesity, Depression, Body mass index, Social isolation

\section{INTRODUCTION}

In recent years, obesity has become a major health issue in the US and worldwide. The World Health Organization estimated that, as of $2007,74.1 \%$ of Americans over 15 years old were overweight, and the US ranked ninth in the world in terms of obesity [1]. The growth of obesity is also remarkable: $19.4 \%$ in $1997,24.5 \%$ in 2004 , and $26.6 \%$ in 2007 [2].

Mental disorders may be an important issue related to obesity. Approximately $25 \%$ of all adults in the US (approximately 57.7 million Americans) have been reported to experience some mental health disorder each year [3]. Psychologists have found that obesity is considered a "stigma" because it is con-

Received: April 26, 2017 Accepted: June 19, 2017

Corresponding author: Beomsoo Kim, PhD

145 Anam-ro, Seongbuk-gu, Seoul 02841, Korea

Tel: +82-2-3290-2204, Fax: +82-2-3290-2204

E-mail: kimecon@korea.ac.kr

This is an Open Access article distributed under the terms of the Creative Commons Attribution Non-Commercial License (http://creativecommons.org/licenses/by$\mathrm{nc} / 4.0 / /$ which permits unrestricted non-commercial use, distribution, and reproduction in any medium, provided the original work is properly cited. ceptualized as a form of physical deviance [4]. According to Goffman [5], obese individuals are even viewed as "not quite human" and subject to discrimination or avoidance. Richardson et al. [6] conducted several experiments to rank preferences for 6 images of individuals (those with no physical handicap or some physical handicap and 10-year-old or 11-year-old obese children). They found consistent preferences for no handicap over some handicap. Remarkably, the least preferred image was always that of obese children $[7,8]$. The stigma attached to obesity may generate considerable stress, which can lead to mental health disorders.

Although the precise mechanism that causes depression remains unclear, textbook causes known thus far include social isolation, abuse, certain medications such as cholesterol-reducing drugs, the death or loss of a significant other, genetic factors, serious illness, and substance abuse [9]. Therefore, social isolation due to the stigma attached to obesity might trigger depression. If obesity increases the likelihood of a mental disorder, then the true cost of obesity may be higher than has been estimated thus far.

Several studies have examined the relationship between 
obesity and depression [10-12], but no study has analyzed their causal relationship. The first issue to consider is bias due to omitted variables. As Faith et al. [11] and Comings et al. [13] report, the common gene ObD7s1875 may make people obese and depressed simultaneously, and omitting this gene may be another source of upward bias for the ordinary least squares estimator. Unobserved individual characteristics may be another relevant factor. If an individual shows a high discount rate (i.e., emphasizes the present), then he or she may overeat and engage in other unhealthy behaviors, such as smoking or avoiding exercise. Another source of endogeneity is reverse causality, according to which depressed individuals may overeat or undereat [14], which may generate an upward or downward bias.

This paper attempted to characterize the causal relationship between obesity and depression by using a pseudo-panel approach. In particular, we dealt with endogeneity introduced by omitting unobservable factors such as the ObD7s1875 gene and other time-invariant unobservable individual characteristics.

\section{METHODS}

We used the Behavioral Risk Factor Surveillance System (BRFSS), which is an annual cross-sectional survey of the adult population (18 years of age or over). The BRFSS is a nationally representative sample based on a phone survey using both landlines and cell phones, and was established in 1984, covering 15 states. It has one of the largest numbers of observations with state identifiers, making it the best dataset available for this paper. We used the BRFSS data from the 1997-2008 period, during which the survey used consistent measures of depression variables.

Depression, a measure of mental disorder, was calculated as the number of days that the respondent felt not good during the last 30 days due to stress, depression, or problems with emotions. For instance, a score of 3.37 means that a respondent had 3 days that they did not feel good in a month. We also defined depression as a binary variable, with a respondent considered to be depressed if he or she felt bad on more than half of the days of the month. Based on descriptive statistics, $7 \%$ of the BRFSS population was classified as depressed for the sample period (Table 1). The key independent variable was obesity, which was measured by the body mass index (BMl; weight in kilograms divided by the square of height in meters).
Table 1. Descriptive statistics

\begin{tabular}{|c|c|c|}
\hline & Mean & SD \\
\hline \multicolumn{3}{|l|}{ Outcomes } \\
\hline Depression (d/mo) & 3.37 & 7.56 \\
\hline Depressed (depression $\geq 16 \mathrm{~d} / \mathrm{mo}$ ) & 0.07 & 0.26 \\
\hline \multicolumn{3}{|l|}{ Obesity } \\
\hline Body mass index $\left(\mathrm{kg} / \mathrm{m}^{2}\right)$ & 26.94 & 5.36 \\
\hline \multicolumn{3}{|l|}{ Demographic variables } \\
\hline Age (y) & 49.95 & 16.80 \\
\hline Male & 0.41 & 0.49 \\
\hline \multicolumn{3}{|l|}{ Race } \\
\hline White & 0.85 & 0.36 \\
\hline Black & 0.08 & 0.27 \\
\hline Others & 0.07 & 0.26 \\
\hline Hispanic & 0.06 & 0.24 \\
\hline Married & 0.56 & 0.50 \\
\hline \multicolumn{3}{|l|}{ Education } \\
\hline Less than high school & 0.09 & 0.29 \\
\hline High school graduate & 0.30 & 0.46 \\
\hline Some college & 0.27 & 0.45 \\
\hline Bachelor's degree or higher & 0.33 & 0.47 \\
\hline \multicolumn{3}{|l|}{ Annual household income (US dollar) } \\
\hline$<10000$ & 0.05 & 0.23 \\
\hline $10000-15000$ & 0.06 & 0.24 \\
\hline $15000-20000$ & 0.08 & 0.27 \\
\hline $20000-25000$ & 0.10 & 0.30 \\
\hline $25000-35000$ & 0.14 & 0.35 \\
\hline $35000-50000$ & 0.18 & 0.38 \\
\hline $50000-75000$ & 0.17 & 0.38 \\
\hline$\geq 75000$ & 0.22 & 0.41 \\
\hline Observations (n) & \multicolumn{2}{|c|}{2433848} \\
\hline
\end{tabular}

Data from Behavioral Risk Factor Surveillance System, 1997-2008.

The sample included individuals aged 18 and over. The depression measure reflects mental health, which includes stress, depression, and problems with emotions.

Participants were asked to identify for how many days during the past 30 days their mental health was not good.

We constructed pseudo-panel data for the analysis. Deaton [15] suggested the use of cohorts to estimate a fixed-effects model from repeated cross-sections. In his approach, individuals sharing some common characteristics are grouped into cohorts, after which the averages within these cohorts are treated as observations of a pseudo-panel $[16,17]$. Importantly, panel data allow researchers to account for unobservable individual heterogeneity, such as the ObD7s1875 gene or other time-invariant unobservable characteristics. Although our data set was not originally a panel data set, we were able to at least approximately account for individual heterogeneity that 
may have caused a spurious correlation between BMI and depression by grouping the individuals into homogenous units and constructing pseudo-panel data. Nonetheless, pseudopanel data are not genuine panel data. Importantly, if a group consists of very different individuals over different periods, then observations in each pseudo-panel would not share similar genes and unobservable characteristics, and the advantage of constructing the pseudo-panel would be limited. Therefore, it is important that the grouping is done so that each person is likely to remain in the same group over time. Thus, we constructed pseudo-panel data sets based on individuals' physical and socioeconomic backgrounds. It is possible that the constructed groups were still heterogeneous over time, so we considered multiple levels of pseudo-panel data in order to obtain as much information as possible.

The simplest form is the representative agent for each state and time. Time is measured by year and month together. For example, January 1997 is a unit of time. For every group and period, we averaged the variables and formed a pseudo-panel data set. We constructed 4 more pseudo-panels by adding sex, marital status, race (ethnic group separately), and education level, one by one, starting from the simplest state and time pseudo-panel. That is, a group in the second pseudo-panel in a period was constructed by averaging values among individuals of the same gender living in the same state. In the third pseudo-panel, each group in the second pseudo-panel was further divided into subgroups by marital status. The last 2 panel data sets were constructed by adding race and education level successively to the grouping criteria in the previous criteria. The econometric model for the estimations is given as follows:

$$
Y_{i t}=\beta_{0}+\beta_{1} B M l_{i t}+\beta_{2} X_{i t}+a_{i}+u_{i t}
$$

where $Y_{i t}$ is the measure of mental health outcomes for unit $i$ in the pseudo-panel, calendar year and month are indicated by $t, a_{i}$ refers to the unobserved group-specific effects, $u_{i t}$ is the error term, and $X$ includes sex, marital status, race (white, black, and other), Hispanic ethnicity, education (no high school diploma, high school diploma, some college, college diploma or higher), age, annual household income (in US dollar [USD]) (<10 000, $10000-15000,15000-20000,20000-25000,25000$ $35000,35000-50000,50000-75000$, and $\geq 75000$ ), and year and month dummies accounting for long-run trends and common seasonal variability.

\section{RESULTS}

We present the pseudo-panel regression results in Table 2 . The Hausman test suggested that the group fixed effects were correlated with the explanatory variables. The first column of Table 2 shows the results for the simplest pseudo-panel data. Every 1-unit increase in the BMI increased depression by 0.159 days per month. Standard errors (in parentheses) are clustered by panel group. This method provides consistent standard errors if the errors are independent across groups, while arbitrary correlations are allowed within each cluster.

The second column of Table 2 shows results for the pseudogroups of state, time, and sex. In this column, male and female are not in the same group any more. The sample size doubled but the magnitude of the coefficient decreased slightly. As we

Table 2. Effects of obesity on depression

\begin{tabular}{|c|c|c|c|c|c|}
\hline \multirow{2}{*}{ Independent variables } & \multicolumn{5}{|c|}{ Depression (d/mo) } \\
\hline & (1) & (2) & (3) & (4) & (5) \\
\hline \multicolumn{6}{|l|}{ Obesity } \\
\hline$(\mathrm{SE})^{1}$ & $(0.061)$ & $(0.030)$ & $(0.018)$ & $(0.008)$ & $(0.004)$ \\
\hline Reference group ${ }^{2}$ & State, year, month & (1)+ male & (2)+ married & (3)+race, Hispanic & (4)+ education \\
\hline Hausman test $\left(\chi^{2}\right)$ & 41.50 & 314.70 & 340.13 & 242.67 & 348.22 \\
\hline (p-value) & $(0.003)$ & $(<0.001)$ & $(<0.001)$ & $(<0.001)$ & $(<0.001)$ \\
\hline
\end{tabular}

The dependent variable was depression, and the independent variables were body mass index, age, household income level, the yearly fixed effect, and the monthly fixed effect.

${ }^{1}$ Clustered standard errors (SEs) by reference group level are provided.

${ }^{2}$ Reference group means the level of pseudo panel constructed and ' + ' means added pseudo panel level to the specified column.

${ }^{* *} p<0.01$. 
considered marital status additionally, the coefficient of interest became 0.104, which means that a 1-unit increase in BMI led to 0.1 additional depressed days. Considering race, ethnicity, and education level improved the precision substantially, although the coefficient was robust for these criteria. The specification in column 5 means the following: a 1-unit increase of BMI would increase depression days by 0.093 , which is $2.8 \%$ of the sample mean (3.37). This finding was statistically significant at a $99 \%$ confidence level.

The magnitude of this estimate can be interpreted as follows. The average BMI increased by 1.64 from 25.8 to $27.5 \mathrm{~kg} / \mathrm{m}^{2}$ during this period, which was associated with $0.15252(=0.093 \times$ 1.64) more depression days per month. Since the depression days per month increased by 0.29 , increases in BMI would explain $53 \%$ of the total variation in depression days per month based on our estimation. This is a remarkably large magnitude, but it should be interpreted with caution. In particular, considering that the pseudo-panel approach does not account for reverse causality, although it deals with omitted unobservable effects, we admit the possibility that this result describes correlation. It is nonetheless possible to draw more positive implications. If the depressed are more likely to overeat than to undereat, this effect would act as an upper bound. If both tendencies cancel out, the effect would be closer to the true causal effects.
Further research is warranted regarding this issue.

Table 3 presents the results from a robustness check. The first concern was specifying the functional form for the obesity measure. We tried a quadratic specification and found a Ushape. A BMl of $20.8 \mathrm{~kg} / \mathrm{m}^{2}$ showed the minimum risk for depression, and as shown in the third and fourth columns, we found that thin people showed a statistically significant negative relationship with depression. However, obese people presented a statistically significant increase in depression. In the bottom panel of Table 3, we show the results using a binary specification of the dependent variable (depression). We defined an individual to be depressed if he or she felt depressed for more than 16 days per month, and this variable was averaged for the individuals in each pseudo-panel group. Thus, the 'depressed' variable was the proportion of those who felt depressed for more than 16 days per month out of the population of the group. A 1-unit increase of BMI increased the probability of being depressed by 0.3 percentage points, which is $4.2 \%$ of the sample mean (7.0\%). This was statistically significant. During this sample period (1997-2008) the percentage of the depressed population increased from 6.3 to $7.4 \%$ in our data, as shown in Figure 1, which is a 1.1 percentage point increase. The BMI increase during the same period would explain 0.5 percentage points of the increase $(=0.003 \times 1.64)$,

Table 3. Effects of obesity on depression as a continuous and categorical variable

Subsample by minimum risk

BMI $\leq \mathbf{2 0 . 8}$

BMI $>20.8$

\begin{tabular}{|c|c|c|c|c|}
\hline \multicolumn{5}{|l|}{ Depression (d/mo) } \\
\hline \multirow[t]{2}{*}{$\mathrm{BMI}$} & $0.093^{* *}$ & $-0.208^{* *}$ & $-0.230^{* *}$ & $0.111^{* *}$ \\
\hline & $(0.004)$ & (0.034) & $(0.082)$ & $(0.004)$ \\
\hline \multirow[t]{2}{*}{$\mathrm{BMI}^{2}$} & \multicolumn{4}{|c|}{$0.005^{* *}$} \\
\hline & \multicolumn{4}{|c|}{$(0.001)$} \\
\hline $\mathrm{R}^{2}$ & 0.023 & 0.024 & 0.019 & 0.024 \\
\hline Observations (n) & 285334 & 285334 & 9853 & 275481 \\
\hline \multicolumn{5}{|c|}{ Depressed ( $\geq 16$ depression, $\mathrm{d} / \mathrm{mo}$ ) } \\
\hline \multirow[t]{2}{*}{ BMI } & $0.003^{* *}$ & $-0.007^{* *}$ & $-0.008^{* *}$ & $0.003^{* *}$ \\
\hline & $(0.0001)$ & $(0.001)$ & (0.003) & (0.0002) \\
\hline \multirow[t]{2}{*}{$\mathrm{BMI}^{2}$} & \multicolumn{4}{|c|}{$0.0002^{* *}$} \\
\hline & \multicolumn{4}{|c|}{$(0.00002)$} \\
\hline $\mathrm{R}^{2}$ & 0.016 & 0.016 & 0.013 & 0.017 \\
\hline Observations (n) & 285334 & 285334 & 9853 & 275481 \\
\hline
\end{tabular}

The dependent variables were depression (as a continuous variable) and being depressed (as a categorical variable), and the independent variables were BMI, BMl², age, household income level, the yearly fixed effect, and the monthly fixed effect.

Clustered standard errors by reference group level are provided in parentheses.

BMI, body mass index $\left(\mathrm{kg} / \mathrm{m}^{2}\right)$.

${ }^{* *} p<0.01$ 


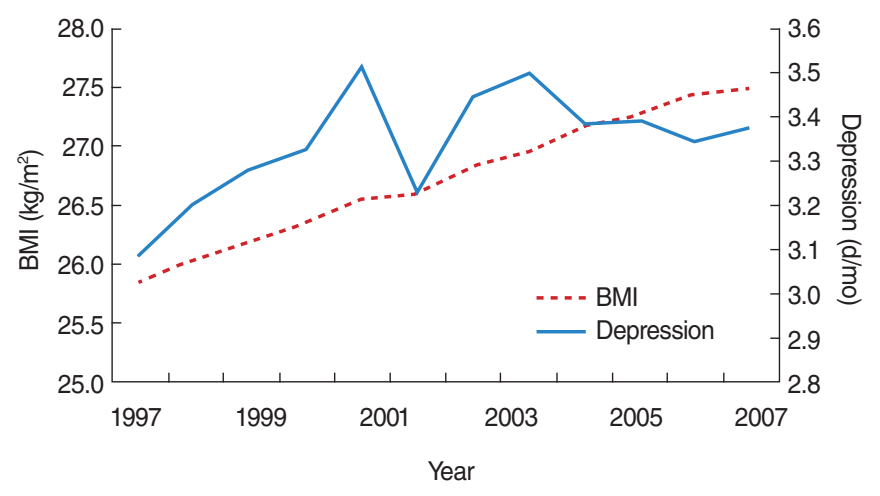

Figure 1. Trends in body mass index (BMI) and depression days per month.

corresponding to $45.0 \%$ of the total variation in the percentage of the depressed population. This is a tremendous change in magnitude, and is similar to what was derived from the results in Table 2.

\section{DISCUSSION}

The prevalence of obesity has been rising for at least 5 decades [18], and mental illness is widespread. Scott et al. [19] conducted a cross-sectional survey across 13 countries and found a statistically significant association between obesity and depressive disorders. McElroy et al. [12] also found that mood disorders and obesity may be related to each other. However, neither of the above studies could clarify the direction or nature of the relationship observed due to endogeneity.

We examined the effects of obesity on mental health using the BRFSS, which is a nationally representative survey. We attempted to account for endogeneity introduced by omitting important unobservable factors by using a pseudo-panel approach and found that the association was still statistically significant.

There remains the issue of reverse causality. For example, a depressed individual may overeat or undereat. If the former, our estimates overstate the causal effects. Our pseudo-panel data do not resolve the reverse causality issue. Ideally, legitimate and relevant instrumental variables would provide a solution if they can be found. We leave this interesting topic for future research.

Our finding has an important policy implication. Based on the Medical Expenditure Panel Survey, 36.2 million people in the US paid for mental health services, with expenditures totaling USD 57.5 billion in 2006 [20]. Currently the economic costs of obesity range from USD 147 billion to nearly USD 210 billion per year [21]. These estimated costs, however, do not include the adverse impacts of mental health conditions. If we take this into account, the cost of obesity would increase. Recently, countries such as Japan and Denmark have introduced a 'fat tax', and some schools have removed vending machines. Evidence from this paper can be used to support these social movements.

\section{ACKNOWLEDGEMENTS}

This research was supported by the National Research Foundation of Korea Grant funded by the Korean Government (NRF-2014-S1A3A2-044238) and Korea University (K1613541).

\section{CONFLICT OF INTEREST}

The authors have no conflicts of interest associated with the material presented in this paper.

\section{ORCID}

Hyungserk Ha http://orcid.org/0000-0003-3814-4053

Beomsoo Kim http://orcid.org/0000-0001-7468-7448

\section{REFERENCES}

1. Streib L. World's fattest countries; 2007 Feb 8 [cited 2017 Jul 11]. Available from: https://www.forbes.com/2007/02/07/ worlds-fattest-countries-forbeslife-cx_Is_0208worldfat.html.

2. Centers for Disease Control and Prevention. National Health and Nutrition Examination Surve; 1997, 2004, 2007 [cited 2017 Jul 11]. Available from: https://www.cdc.gov/nchs/nhanes/index.htm.

3. US Department of Health and Human Services. Mental health: a report of the Surgeon General; 1999 [cited 2017 Jul 11]. Available from: https://profiles.nlm.nih.gov/ps/access/NNBBHT.pdf.

4. DeJong W. The stigma of obesity: the consequences of naive assumptions concerning the causes of physical deviance. J Health Soc Behav 1980;21(1):75-87.

5. Goffman E. Stigma: notes on the management of spoiled identity. Englewood Cliffs: Prentice-Hall; 1963, p. 1-40.

6. Richardson SA. Goodman N, Hastorf AH, Dornbusch SM. Cultural uniformity in reaction to physical disabilities. Am Sociol 
Rev 1961;26(2):241-247.

7. Maddox GL, Back KW, Liederman WR. Overweight as social deviance and disability. J Health Soc Behav 1968;9(4):287298.

8. Matthews V, Westie C. A preferred method for obtaining rankings: reactions to physical handicaps. Am Sociol Rev 1966;31 (6):851-854.

9. University of Maryland Medical Center. Depression [cited 2017 Jul 2]. Available from: http://www.umm.edu/health/ medical/altmed/condition/depression.

10. de Wit LM, van Straten A, van Herten M, Penninx BW, Cuijpers P. Depression and body mass index, a U-shaped association. BMC Public Health 2009;9:14.

11. Faith MS, Matz PE, Jorge MA. Obesity-depression associations in the population. J Psychosom Res 2002;53(4):935-942.

12. McElroy SL, Kotwal R, Malhotra S, Nelson EB, Keck PE, Nemeroff CB. Are mood disorders and obesity related? A review for the mental health professional. J Clin Psychiatry 2004;65(5): 634-651.

13. Comings DE, Gade R, MacMurray JP, Muhleman D, Peters WR. Genetic variants of the human obesity (OB) gene: association with body mass index in young women, psychiatric symptoms, and interaction with the dopamine D2 receptor (DRD2) gene. Mol Psychiatry 1996;1(4):325-335.

14. Mueller C, Field T, Yando R, Harding J, Gonzalez KP, Lasko D, et al. Under-eating and over-eating concerns among adolescents. J Child Psychol Psychiatry 1995;36(6):1019-1025.

15. Deaton A. Panel data from time series of cross-sections. J Econom 1985;30(1-2):109-126.

16. Verbeek M., Nijman T. Can cohort data be treated as genuine panel data? Empir Econ 1992;17(1):9-23.

17. Verbeek M. Pseudo-panels and repeated cross-sections. In: Mátyás $L$, Sevestre $P$, editors. The econometrics of panel data: handbook of theory and applications. Berlin: Springer; 2008, p. 369-383.

18. Burkhauser RV, Cawley J, Schmeiser MD. The timing of the rise in U.S. obesity varies with measure of fatness. Econ Hum Biol 2009;7(3):307-318.

19. Scott KM, Bruffaerts R, Simon GE, Alonso J, Angermeyer M, de Girolamo $G$, et al. Obesity and mental disorders in the general population: results from the world mental health surveys. Int J Obes (Lond) 2008;32(1):192-200.

20. National Institute of Mental Health. Mental healthcare cost data for all Americans (2006) [cited 2016 Nov 17]. Available from: https://www.nimh.nih.gov/health/statistics/cost/mental-healthcare-cost-data-for-all-americans-2006.shtml.

21. Cawley J, Meyerhoefer C. The medical care costs of obesity: an instrumental variables approach. J Health Econ 2012;31(1): 219-230. 